\title{
Comparison of Clinical Efficacy of Laparoscopic-Assisted and Laparotomy D2 Radical Total Gastrectomy for Advanced Gastric Cancer
}

\author{
FUQUAN JIANG, PEIMING SUN, MANKU DONG, HEMING. YANG, HAIGUANG LIN, JING XIN LIU, JIANWU \\ YANG AND HONGFENG YAN*
}

Department of General Surgery, People's Liberation Army Strategic Support Force Medical Center, Beijing 100101, China

\begin{abstract}
Jiang et al.: Laparoscopic-Assisted and Laparotomy D2 Radical Total Gastrectomy for Advanced Gastric Cancer
\end{abstract}
To investigate the clinical efficacy of laparoscopic-assisted and laparotomy D2 radical total gastrectomy for advanced gastric cancer. From January 2014 to January 2015, 81 patients with advanced gastric cancer were divided into study group $A(n=41)$ for laparoscopic-assisted therapy and study group $B(n=40)$ for laparotomy D2 radical total gastrectomy according to different surgical methods. Postoperative followup was 60 mo. Perioperative period indicators, curative effect and complications were recorded and compared between the two groups. The operation time of study group A was significantly longer than that of study group B. The hospital stay, intraoperative blood loss, incision length and intestinal function recovery of study group $A$ were significantly less than that of study group $B$ and the difference had statistical significance $(\mathbf{p}<\mathbf{0 . 0 5})$. Compared with study group $B$, the number of lymph node dissection, the number of positive lymph nodes and the average survival time in study group $A$ were less and the rate of lymph node metastasis, the distance from distal resection margin and the distance from proximal resection margin were large, but the difference had no statistical significance $(p>0.05)$. The difference of complications and recurrence rate between study group $A$ and study group $B$ had no statistical significance $(p>0.05)$. Laparoscopic-assisted treatment for advanced gastric cancer is less invasive, has a shorter recovery time and the outcome and survival time of lymphadenectomy is comparable to those of laparotomy.

Key words: Advanced gastric cancer, laparoscopic surgery, laparotomy, total gastrectomy, lymph node dissection

Gastric cancer is caused by gastric mucosal disease and its incidence is second only to lung cancer in China. It is a digestive system tumor with very high mortality ${ }^{[1]}$. With the development of society, the change of people's life style and living habits leads to the increasing incidence of gastric cancer. In recent years, young people tend to stay up late, work overtime, eat and work irregularly. Because there is no typical symptom in the early stage of gastric cancer, it is easy to miss diagnosis and misdiagnosis. At the time of consultation, the disease condition is mostly in the stage of progression, the disease is developing rapidly, it is easy to spread and metastasize and the risk of death is very high ${ }^{[2]}$. Chemoradiotherapy is an effective supplement for advanced gastric cancer, but its long-term effect is poor.
Surgical resection of malignant tumor is the first choice for treatment of gastric cancer ${ }^{[3]}$. In the past, many patients received radical gastrectomy using laparotomy, which could remove the lesion to the maximum extent, with wide field of view and prolong the survival time. However, the abdominal exposure was a lot, the trauma was great and it was easy to cause complications, thus affecting the therapeutic efficacy, which was not conducive to the recovery of prognosis ${ }^{[4]}$.

With advances in medical technology, laparoscopic techniques are widely used for clinical surgical treatment. Laparoscopic-assisted treatment refers to the completion of all operations related to surgery under laparoscope. This method is small in trauma and can be completed only by making a small incision. The

*Address for correspondence

E-mail: yanhongfeng2008@163.com 
postoperative scar is very small, which is favored by most patients with gastric cancer. D2 radical gastrectomy is the most commonly used surgical method in radical gastrectomy for cancer, which can thoroughly dissect perigastric lymph nodes ${ }^{[5]}$. In recent years, most studies have shown that laparoscopic radical gastrectomy has the advantages of minimally invasive, safe and effective, but it is difficult for advanced radical gastrectomy, especially for distal operation and there may be residual risk of lesions. The efficacy of laparoscopic radical gastrectomy in clinical treatment is controversial and needs further exploration ${ }^{[6]}$. In this study, 81 patients with advanced gastric cancer in our hospital were treated with the above two methods respectively and the therapeutic effects of the two groups were compared to provide some evidences for clinical treatment.

\section{MATERIALS AND METHODS}

\section{General data:}

A total of 81 patients with advanced gastric cancer diagnosed and treated in our hospital from January 2014 to January 2015 were selected for this study, including 46 males and 35 females, aged 29-78 y, with mean age of (50.41 110.57$) \mathrm{y}$, tumor diameter of $2-5 \mathrm{~cm}$ and mean diameter of $(3.90 \pm 1.31) \mathrm{cm}$. The patients were divided into study group A $(n=41)$ for laparoscopic-assisted therapy and study group B $(n=40)$ for laparotomy D2 radical total gastrectomy according to different surgical methods.

\section{Inclusion criteria and exclusion criteria:}

Inclusion criteria-Patients diagnosed with gastric cancer by pathological biopsy; patients without distant metastasis by preoperative imaging physical examination; patients without metastasis by intraoperative exploration; patients with complete clinical data; patients aged $\geq 29$ y and $\leq 78$ y; patients with successful follow-up.

Exclusion criteria-Patients with heart, liver and renal insufficiency; patients with other malignant tumors; patients with metastasis; tumor diameter greater than 6 $\mathrm{cm}$; abdominal mass, diffuse peritonitis, diaphragmatic hernia and abdominal hernia, etc.

\section{Methods:}

Study group A; laparoscopic-assisted D2 radical gastrectomy. The patient was placed in the supine position, intubated with an endotracheal tube, under general anesthesia and a trocar tube was placed in the five-hole method to establish pneumoperitoneum. The abdominal cavity was explored to determine the location of tumor and ultrasound knife was used to divide greater omentum along transverse colon and to separate hepatic flexure of colon; into fascial space, the root was used to divide right gastroepiploic artery and right vein and to dissect lymph node in the group 6 . The greater omentum and spleen were dissected, the left gastroepiploic artery and vein were dissected and the group 4 was dissected. The greater omentum was placed under the liver, the stomach was turned to the cranial side, the pancreas capsule was removed, the pancreas was separated tightly, the proximal part of splenic artery was exposed and the group 11 was dissected; the left gastric artery was dissected away from the abdomen and celiac artery and the groups 7 and 9 were dissected; the common hepatic artery was exposed, the upper part of the liver was separated and the group 8 was dissected; the duodenum was exposed in the hepatic artery, the hepatoduodenal ligament was opened and the group 12 of lymph nodes was dissected; the $3^{\text {rd }}$ lymph node was dissected along the small curve of the gastric wall to the cardia; after dissection, free the lower esophageal segment, use a cutting sealer to cut the duodenum of the patient at $3 \mathrm{~cm}$ distal to pylorus, perform incision at $6 \mathrm{~cm}$ upward on the abdomen, divide the lower esophageal end, place the stapler, perform esophagojejunostomy, perform Brown anastomosis between jejunal input loop and output loop to reconstruct the digestive tract, after the operation, place the feeding tube and drainage tube, close the abdominal cavity.

Study group B; laparotomy D2 radical total gastrectomy. The incision was made in the middle abdomen of the patient (18-20 cm in length) and entered the abdominal cavity. Based on tumor location exploration, lymph node dissection and digestive tract reconstruction were the same as those in study group A. Patients in both groups were followed up for 60 mo after operation.

\section{Observational indexes:}

To collect general clinical data of patients, including gender, height, weight, age, tumor location, tumor diameter, tumor stage, grade and body mass index (BMI); Perioperative period indicators: Incision length, surgical operation time, intraoperative blood loss, hospital stay and intestinal recovery time were recorded. Surgical curative effect: The number of lymph node dissection, lymph node metastasis rate, number of positive lymph nodes, distance from distal resection margin, distance from proximal resection 
margin and average survival time etc., were recorded. Postoperative complications: After a follow-up of 30 mo, the occurrence and recurrence of complications were compared; including incision infection, gastroplegia, anastomotic leakage, hemorrhage, pulmonary infection and duodenal leakage.

\section{Statistical methods:}

Statistical data were analyzed using statistical package for the social sciences (SPSS) 23.0 software. For the measurement data with normal distribution, $\overline{\mathrm{x}} \pm \mathrm{S}$ is used as t-test; for the enumeration data, $\mathrm{n}(\%)$ is used as $\chi^{2}$-test. The difference was considered statistically significant when $\mathrm{p}<0.05$.

\section{RESULTS AND DISCUSSION}

There was no significant difference but comparability in general clinical data between the two groups $(\mathrm{p}>0.05)$ (Table 1).

Comparison of perioperative period indicators between the two groups were done. The operation time of study group A was significantly longer than that of study group B and the difference had statistical significance $(\mathrm{p}<0.05)$; the hospital stay, intraoperative blood loss, incision length and intestinal function recovery of study group A were significantly less than that of study group B and the difference had statistical significance $(\mathrm{p}<0.05)$ (Table 2).

Comparison of curative effect between two groups was observed. The number of lymph node dissection and number of positive lymph nodes and mean survival time of study group A were less than that of study group B, while the rate of lymph node metastasis, distance from distal resection margin and distance from proximal resection margin of study group A were greater than that of study group B, but the differences had no statistical significance $(\mathrm{p}>0.05)$ (Table 3$)$.

Comparison of incidence and recurrence of complications between the two groups were measured. The complications in study group A were less than those in study group B and the incidence rate was low. The recurrence rate in study group A was higher than that in study group B, but the difference had no statistical significance $(p>0.05)$ (Table 4).

\section{TABLE 1: COMPARISON OF GENERAL CLINICAL DATA BETWEEN THE TWO GROUPS}

\begin{tabular}{|c|c|c|c|c|c|}
\hline General data & & $\begin{array}{l}\text { Study group } A \\
(n=41)\end{array}$ & $\begin{array}{c}\text { Study group B } \\
(\mathrm{n}=40)\end{array}$ & $\mathrm{t} / \chi^{2}$ value & $\mathrm{p}$ value \\
\hline Mean age $(\mathrm{y})$ & & $51.23 \pm 11.05$ & $49.56 \pm 10.03$ & 0.932 & 0.095 \\
\hline $\operatorname{BMI}\left(\mathrm{kg} / \mathrm{m}^{2}\right)$ & & $22.13 \pm 1.17$ & $22.07 \pm 1.12$ & 0.687 & 0.201 \\
\hline \multirow{2}{*}{ Gender (case) } & Male & $24(58.54)$ & $22(55.00)$ & \multirow{2}{*}{0.743} & \multirow{2}{*}{0.158} \\
\hline & Female & $17(41.46)$ & $18(45.00)$ & & \\
\hline Tumor size $(\mathrm{cm})$ & & $3.96 \pm 1.45$ & $3.87 \pm 1.39$ & 0.824 & 0.139 \\
\hline \multirow{2}{*}{$\begin{array}{l}\text { Tumor location } \\
\text { (case) }\end{array}$} & $\begin{array}{l}\text { Upper part of } \\
\text { stomach }\end{array}$ & $18(43.90)$ & $15(37.50)$ & \multirow{2}{*}{0.713} & \multirow{2}{*}{0.241} \\
\hline & $\begin{array}{l}\text { Middle part of } \\
\text { stomach }\end{array}$ & $23(56.10)$ & $25(62.50)$ & & \\
\hline \multirow{4}{*}{$\mathrm{N}$ stage (case) } & $\mathrm{N}_{0}$ & $16(39.02)$ & $14(35.00)$ & \multirow{4}{*}{0.875} & \multirow{4}{*}{0.103} \\
\hline & $\mathrm{N}_{1}$ & $6(14.63)$ & $7(17.50)$ & & \\
\hline & $\mathrm{N}_{2}$ & $7(17.07)$ & $8(40.00)$ & & \\
\hline & $\mathrm{N}_{3}$ & $12(29.27)$ & $11(27.50)$ & & \\
\hline \multirow{3}{*}{$\begin{array}{l}\text { Tumor } \\
\text { differentiation } \\
\text { degree (case) }\end{array}$} & High differentiation & $9(21.95)$ & $7(17.50)$ & \multirow{3}{*}{0.692} & \multirow{3}{*}{0.186} \\
\hline & $\begin{array}{l}\text { Medium and low } \\
\text { differentiation }\end{array}$ & $32(78.05)$ & $33(82.50)$ & & \\
\hline & $\mathrm{T}_{2}$ & $5(12.19)$ & $3(7.50)$ & & \\
\hline \multirow[t]{2}{*}{ T stage (case) } & $\mathrm{T}_{3}$ & $4(9.76)$ & $6(15.00)$ & \multirow[t]{2}{*}{0.713} & \multirow[t]{2}{*}{0.174} \\
\hline & $\mathrm{T}_{4}$ & $32(78.05)$ & $31(77.50)$ & & \\
\hline
\end{tabular}


www.ijpsonline.com

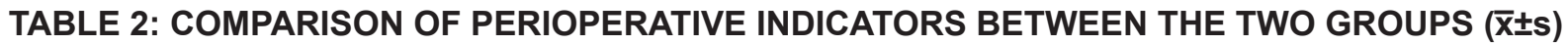

\begin{tabular}{lcccc}
\hline Items & Study group A $(\mathrm{n}=41)$ & Study group B $(\mathrm{n}=40)$ & $\mathrm{t}$ value & $\mathrm{p}$ value \\
\hline Operation time $(\mathrm{min})$ & $250.23 \pm 32.96$ & $215.25 \pm 27.63$ & 8.642 & 0.003 \\
Hospital stay (d) & $14.01 \pm 3.25$ & $16.15 \pm 3.59$ & -6.716 & 0.019 \\
Intraoperative blood & $72.41 \pm 15.57$ & $97.82 \pm 12.50$ & -5.693 & 0.006 \\
loss $(\mathrm{ml})$ & $5.99 \pm 0.76$ & $19.01 \pm 1.23$ & 6.921 & 0.015 \\
Length of incision $(\mathrm{cm})$ & $2.98 \pm 1.27$ & $3.51 \pm 1.42$ & -4.367 & 0.036 \\
$\begin{array}{l}\text { Intestinal function } \\
\text { recovery (d) }\end{array}$ & & &
\end{tabular}

TABLE 3: COMPARISON OF THE EFFECTS OF RADICAL SURGERY BETWEEN THE TWO GROUPS ( $\overline{\mathbf{x}} \pm \mathbf{s})$

\begin{tabular}{lcccc}
\hline Items & Study group A $(\mathrm{n}=\mathbf{4 1})$ & Study group B $(\mathrm{n}=40)$ & $\mathrm{t} / \chi^{2}$ value & $\mathrm{p}$ value \\
\hline $\begin{array}{l}\text { Number of lymph node } \\
\text { dissection (nos.) }\end{array}$ & $25.52 \pm 5.47$ & $27.78 \pm 6.49$ & -1.382 & 0.325 \\
$\begin{array}{l}\text { Lymph node metastasis } \\
\text { rate }(\%)\end{array}$ & $35(85.36)$ & $34(85.00)$ & 0.132 & 0.854 \\
$\begin{array}{l}\text { Number of positive } \\
\text { lymph nodes (nos.) }\end{array}$ & $13.69 \pm 3.20$ & $14.02 \pm 3.37$ & -0.647 & 0.519 \\
$\begin{array}{l}\text { Distance from distal } \\
\text { resection margin (cm) }\end{array}$ & $4.67 \pm 1.10$ & $4.41 \pm 1.05$ & 0.312 & 0.497 \\
$\begin{array}{l}\text { Distance from proximal } \\
\text { resection margin }(\mathrm{cm})\end{array}$ & $7.08 \pm 1.12$ & $6.99 \pm 1.08$ & 0.367 & 0.512 \\
Mean survival time $(\mathrm{y})$ & $3.38 \pm 0.51$ & $3.05 \pm 0.48$ & 2.130 & 0.095 \\
\hline
\end{tabular}

TABLE 4: COMPARISON OF CO-OCCURRENCE AND RECURRENCE BETWEEN THE TWO GROUPS (\%)

\begin{tabular}{|c|c|c|c|c|}
\hline Complication & Study group A $(n=41)$ & Study group $B(n=40)$ & $\chi^{2}$ value & $\mathrm{p}$ value \\
\hline Wound infection & 1 & 2 & & \\
\hline Gastroplegia & 1 & 1 & & \\
\hline Anastomotic fistula & 2 & 1 & & \\
\hline $\begin{array}{l}\text { Anastomotic incision } \\
\text { bleeding }\end{array}$ & 2 & 2 & & \\
\hline Lung infection & 0 & 1 & & \\
\hline Duodenal leakage & 1 & 1 & & \\
\hline Total incidence & $7(17.50)$ & $8(20.00)$ & 0.924 & 0.352 \\
\hline Recurrence rate & $21(51.22)$ & $20(50.00)$ & 0.846 & 0.297 \\
\hline
\end{tabular}

Gastric cancer is the fourth leading cause of life- D2 radical total gastrectomy is the main method to threatening illness worldwide ${ }^{[7]}$. Gastric cancer with cancer cells infiltrating into the submucosa, muscle layer or serosa is called advanced gastric cancer. The risk of distant metastasis is high. It is easy to progress to advanced stage of gastric cancer. If it is not treated in time, it is very harmful to the patient's life and health. Therefore, timely treatment of advanced gastric cancer and control of disease progression are of great significance in improving the prognosis and prolonging the survival time of patients. eradicate advanced gastric cancer. Laparotomy is to make an incision in the abdomen, open the abdominal cavity, remove the focus tissue, dissect the lymph nodes, control the tumor progression and delay the disease condition, with the confirmed therapeutic effect. This surgical method is easy to operate and has a wide application range, but the incision is long, which will cause great damage to the soft tissues of body and there are many complications. It is easy to miss some lymph nodes which are not easy to be found by naked 
eyes. The postoperative recovery time is long and it is not acceptable by patients. With the development of minimally invasive techniques, laparoscopic-assisted D2 radical total gastrectomy was gradually mature and was used for clinical treatment. This surgical method only need to perform small-hole puncture for the patient, use laparoscopic exploration to locate the lesion and remove the lesion, laparoscope can make to view clear position of lymph node, with good visual field and clearly locate the lymph node which is not easily visible to the naked eye, which is beneficial to the complete removal. Not only rapid resection of lesions and efficient dissection of lymph nodes, but also the advantages of minimally invasive surgery can be brought into play. The use of instruments can relieve the pain of patients without extensive soft tissue dissection. The intraoperative definition is high and the operation is more meticulous. It can reduce the damage to peripheral blood vessels and ensure the safe and effective operation. Most studies showed that the shortterm efficacy of laparoscopic-guided surgery in the treatment of gastric cancer was significantly better than that of traditional laparotomy group. However, most studies selected patients with small lesions in the lower part of stomach for prospective trial. Such patients with gastric cancer had good lesion edge identification, easy resection, lower difficulty than those of total gastrectomy, lower postoperative complications and lower mortality than those of laparotomy group ${ }^{[8,9]}$. At present, the clinical application value of laparoscope in treatment of advanced gastric cancer and its influence on prognosis still need to be further studied. Complete lymph node dissection after total gastrectomy under laparoscope is a difficult point in current clinical operation. With the increase in the times of laparoscopic-guided surgery, doctors are more skilled in technique, familiar with perigastric lymph nodes and can operate the device well and reduce blood loss. Li et al. ${ }^{[10]}$ proposed that laparoscopic-guided radical gastrectomy was well tolerated for neoadjuvant chemotherapy.

In this study, the operation time was significantly longer in study group A than in study group B. This may be due to the fact that, under laparoscopic surveillance, there are still certain limitations in the surgical operation, resulting in a prolonged operation time and that the surgical approach requires a high level of practice for the clinician. The results of this study are different from those of Yan et al. ${ }^{[11]}$. This may be due to differences in the selection of study objects and the ability of each hospital physician to perform laparoscopic techniques. The hospital stay, intraoperative blood loss, incision length and recovery time of intestinal function in study group A were significantly less than those in study group B. It indicated that laparoscopicassisted treatment could shorten hospital stay, reduce hemorrhagic volume with small trauma, which was beneficial to gastrointestinal recovery. The study by Wang et al. ${ }^{[12]}$ showed that laparoscope group could shorten the anal drainage and hospital stay. The results of this study were consistent with those of Wang et al. The incision of laparotomy is large, easy to damage the surrounding tissues and organs and to increase the blood loss and may also affect the body's immune function. The amplification effect of laparoscope can well expose blood vessel, make intraoperative anatomy more precise, reduce bleeding risk and reduce blood loss. In this study, there was no significant difference in curative effect between study group A and study group B. A meta-analysis of the pros and cons of open surgery and laparoscopic resection using random effects modeling showed similar risk of short-term mortality and adverse events and no difference in the number of lymph nodes collected, indicating treatment equivalence between the two methods for tumors ${ }^{[13]}$. The results of this study are consistent with those of the above study. The analysis by Jeong et al. ${ }^{[14]}$ showed that postoperative pulmonary complications, intestinal obstruction and wound problems were significantly higher in patients undergoing laparoscopy and in patients with advanced gastric cancer. Therefore, it is necessary to closely monitor the postoperative patients with advanced gastric cancer, so as to reduce the incidence of related complications. Park et al. ${ }^{[15]}$ showed that there was no significant difference in complications and stress response between laparoscopic distal gastrectomy and open gastrectomy and there was no difference in disease-free survival rate 3 y after surgery. In this study, there was no difference in complications and recurrence between the two groups. It is consistent with Park study results.

Limitations of this study, small sample size, retrospective study and short follow-up may result in deviation. Therefore, it is necessary to expand the sample size and conduct prospective study to further clarify the therapeutic efficacy of laparoscopic D2 radical gastrectomy as well as possible advantages, risks and long-term results.

In conclusion, laparoscopic-assisted D2 radical total gastrectomy for advanced gastric cancer had less trauma, shorter gastrointestinal recovery time, similar number of lymph nodes dissection and survival time as 
laparotomy, good clinical efficacy and good safety, thus deserving to be widely used in clinic.

\section{Acknowledgements:}

Fuquan Jiang and Peiming Sun contributed equally to this work.

\section{Conflicts of interest:}

The authors declared no conflict of interest.

\section{REFERENCES}

1. Irino T, Sano T, Hiki N, Ohashi M, Nunobe S, Kumagai K, et al. Diagnostic staging laparoscopy in gastric cancer: a prospective cohort at a cancer institute in Japan. Surg Endosc 2018;32(1):268-75.

2. Kao YC, Fang WL, Wang RF, Li AF, Yang MH, Wu CW, et al. Clinicopathological differences in signet ring cell adenocarcinoma between early and advanced gastric cancer. Gastric Cancer 2019;22(2):255-63.

3. Zhao TT, Xu H, Xu HM, Wang ZN, Xu YY, Song YX, et al. The efficacy and safety of targeted therapy with or without chemotherapy in advanced gastric cancer treatment: a network meta-analysis of well-designed randomized controlled trials. Gastric Cancer 2018;21(3):361-71.

4. Yu J, Huang C, Sun Y, Su X, Cao H, Hu J, et al. Effect of laparoscopic vs. open distal gastrectomy on 3-year diseasefree survival in patients with locally advanced gastric cancer: the CLASS-01 randomized clinical trial. JAMA 2019;321(20):1983-92.

5. Beeharry MK, Zhu ZL, Liu WT, Yao XX, Yan M, Zhu ZG. Prophylactic HIPEC with radical D2 gastrectomy improves survival and peritoneal recurrence rates for locally advanced gastric cancer: personal experience from a randomized case control study. BMC cancer 2019;19(1):1-9.

6. Li Z, Li Z, Zhang L, Liu Q, Wang Z, Zhang Z, et al. Staging laparoscopy for locally advanced gastric cancer in Chinese patients: a multicenter prospective registry study. BMC cancer 2018;18(1):63.

7. Xiao H, Liu W, Quan H, Ouyang Y. Peri-operative blood transfusion does not influence overall and disease-free survival after radical gastrectomy for stage II/III gastric cancer: a propensity score matching analysis. J Gastrointest Surg 2018;22(9):1489-500.
8. Zhang L, Zang L, Sun J, Dong F, Feng B, Lu AG, et al. Longterm outcomes of laparoscopy-assisted gastrectomy for T4a advanced gastric cancer: a single-center retrospective study. Surg Laparosc Endosc Percutan Tech 2019;29(6):476-82.

9. Li K, Cannon JG, Jiang SY, Sambare TD, Owens DK, Bendavid E, et al. Diagnostic staging laparoscopy in gastric cancer treatment: a cost-effectiveness analysis. J Surg Oncol 2018;117(6):1288-96.

10. Li Z, Shan F, Ying X, Zhang Y, Jian-Yu E, Wang Y, et al. Assessment of laparoscopic distal gastrectomy after neoadjuvant chemotherapy for locally advanced gastric cancer: a randomized clinical trial. JAMA Surg 2019;154(12):1093101.

11. Shi Y, Xu X, Zhao Y, Qian F, Tang B, Hao Y, et al. Longterm oncologic outcomes of a randomized controlled trial comparing laparoscopic versus open gastrectomy with D2 lymph node dissection for advanced gastric cancer. Surgery 2019;165(6):1211-6.

12. Wang Z, Xing J, Cai J, Zhang Z, Li F, Zhang N, et al. Shortterm surgical outcomes of laparoscopy-assisted versus open D2 distal gastrectomy for locally advanced gastric cancer in North China: a multicenter randomized controlled trial. Surg Endosc 2019;33(1):33-45.

13. Beyer K, Baukloh AK, Kamphues C, Seeliger H, Heidecke $\mathrm{CD}$, Kreis ME, et al. Laparoscopic versus open gastrectomy for locally advanced gastric cancer: a systematic review and meta-analysis of randomized controlled studies. World J Surg Oncol 2019;17(1):1-9.

14. Jeong SH, Park JH, Choi SK, Hong SC, Jung EJ, Ju YT, et al. High rates of complications in advanced stage gastric cancer after laparoscopic gastrectomy. Korean J Clin Oncol 2017;13(2):113-7.

15. Park YK, Yoon HM, Kim YW, Park JY, Ryu KW, Lee YJ, et al. Laparoscopy-assisted versus open D2 distal gastrectomy for advanced gastric cancer: results from a randomized phase II multicenter clinical trial (COACT 1001). Ann Surg 2018;267(4):638-45.

This is an open access article distributed under the terms of the Creative Commons Attribution-NonCommercial-ShareAlike 3.0 License, which allows others to remix, tweak, and build upon the work non-commercially, as long as the author is credited and the new creations are licensed under the identical terms

This article was originally published in a special issue, "Therapeutic Perspectives in Biomedical Research and Pharmaceutical Sciences and their Nursing Methods"

Indian J Pharm Sci 2021:83(4)Spl issue "96-101" 